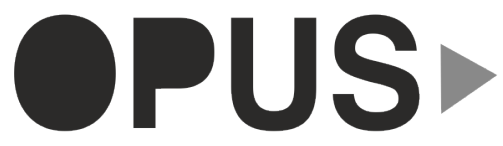

Uluslararası Toplum Araştırmaları Dergisi International Journal of Society Researches
E-ISSN : 2528-9535

YIl Year: 9

Cilt Volume: 11

Sayı Issue : 18

Haziran June 2019

Makalenin Geliş Tarihi Received Date: 12/04/2019 Makalenin Kabul Tarihi Accepted Date: 05/05/2019

\title{
Etik Liderliğin Çalışanlar ve Örgütler Açısından Sonuçları: Kavramsal Bir İnceleme
}

\author{
DOI: $10.26466 /$ opus.553130 \\ *
}

\section{Belgin Bahar $^{*}$}

* Arş. Gör. Dr., Galatasaray Üniversitesi, İ̈BF, İşletme bölümü / İstanbul / Türkiye

E-Posta: belginkaygan@gmail.com

ORCID:0000-0003-3347-3085

\section{Öz}

Günümüzde yaşanan etik skandallar nedeniyle işletmelerde etik konusu ve buna bağh olarak etik liderlik kavramı daha çok önem kazanmaya başlamıştır. Bununla birlikte yazında etik liderlik kavramı ve özellikleri tam olarak tanımlanmamıştır. Ayrıca, söz konusu kavramın yapısı üzerine yazında bazı karışıklıklar olduğu tespit edilmiştir. Bu çalışmanın amacı etik liderlik kavramının yapısının daha iyi anlaşılmasını sağlamak ve etik liderliğin örgüt ve çalışanlar açısından sonuçlarını analiz etmektir. Bu doğrultuda öncelikle ulusal ve uluslararası yazın taranmış ve etik liderlik kavramı açıklanarak kavram karışıklıkları giderilmeye çalışılmıştır. Daha sonra etik liderliğin etki ettiği diğger kavramlarla olan ilişkileri ele alınmıştır. Çalı̧̧manın sonunda etik liderliğin sonuçlarının sentezlendiği kuramsal bir model önerisi yapılmıştır. Bu modele göre etik liderlik davranışları, çalışanların iş tatminini, iyi oluşunu, örgütsel adalet algısını, örgütsel vatandaşlık davranışlarını ve örgütsel bağhllı̆̆ın doğrudan, olumlu yönde etkilemektedir. Çalışma sonunda araştırma kısıtlarına ve gelecek çalışmalara önerilere yer verilmiştir. Bu araştırma etik liderliğin hem örgüt hem de çalışanlar için önemini ortaya koymaktadır.

Anahtar Kelimeler: Etik liderlik, İş tatmini, İyi oluş, Örgütsel adalet, Örgütsel bağlllık 


\title{
The Consequences of Ethical Leadership in Terms of Employees and Organizations: A Conceptual Examination
}

\begin{abstract}
Today, due to the ethical scandals, the ethical issue and the ethical leadership concept in businesses have started to gain more importance for enterprises. However, the concept and characteristics of ethical leadership are not fully defined in the literature. In addition, there was some confusion in the literature on the structure of the concept in question. The aim of this study is to provide a better understanding of the structure of the ethical leadership concept and to analyze the results of ethical leadership for the organization and employees. In this contexte, national and international literature was first reviewed and by explaining the concept of ethical leadership the confusions of concept is tried to be resolved. Then, the relations of ethical leadership with other concepts are discussed. Therefore, a theoretical model was proposed to synthesize the results of ethical leadership. According to this model, ethical leadership affects employees' job satisfaction, well-being, organizational justice perception, organizational citizenship behavior and organizational commitment directly and positively. At the end of the study, research constraints and suggestions for future studies are included. This research reveals the importance of ethical leadership for both the organization and the employees.
\end{abstract}

Keywords: Ethical leadership, Job satisfaction, Well-being, Organizational justice, Organizational commitment 


\section{Giriş}

Etik liderlik kavramı yaşanan etik skandallar nedeniyle işletmelerde büyük önem kazanmıştır (Brown vd., 2005). Günümüzde liderlerin, tüketiciler, çalışanlar, tedarikçiler, hükümetler, yerel topluluklar gibi tüm paydaşlarını içeren topluma karşı ahlaki yükümlülüklerinde daha duyarlı olmaları gerektiğine dair artan bir farkındalık oluşmuştur (Mendonca, 2001). Brown, Treviño ve Harrison (2005), liderlerin çalışanlar için etik konusunda rehberlik etmesi gerektiğini belirtmiştir. Bu bağlamda liderler çal1şanlar için ahlaki bir örnek oluşturmalı ve örgüt faaliyetlerini toplumun değerlerine uygun şekilde gerçekleştirmelidir.

Son yıllarda yeni liderlik teorileri çerçevesinde önemi artan ve yöneticilerin örgütleri için en değerli girdi kaynağı olan insanı ele alırken, onu daha verimli bir şekilde çalışmaya yönlendireceği önemli liderlik biçimlerinden birisi etik liderliktir (Akdoğan ve Demirtaş, 2014). Genel olarak, etik liderlik, başkalarının haklarına ve onuruna saygılı bir şekilde liderlik etmeyi ifade etmektedir (Ciulla, 2004). Etik liderlik, liderlerin aldıkları kararlarda, uyguladıkları eylemlerde güçlerini nasıl kullandıklarıyla ilgili bir liderlik biçimidir. Bu liderlik şeklinin en önemli güç ve etki kaynağ1 ahlaki ve etik otoriteye dayanmaktadır (Akdoğan ve Demirtaş, 2014).

Pek çok araştırmacı kavramın önemini vurgulamış ve yazında teorik ya da ampirik çalışma sayısının azlığına dikkat çekmişlerdir (örneğin, Brown vd., 2005; Shin vd., 2015). Özellikle de Türkçe yazında etik liderlik konusuna sınırlı sayıda araştırmada yer verilmektedir (Akdoğan ve Demirtaş, 2014). Bu makalede etik liderliği tanımlayıcı bakış açısıyla incelenmesi ve şu sorulara yanıt bulmak amaçlanmaktadır: Etik liderlik kavramı tam olarak ne ifade etmektedir? Etik liderliği diğer liderlik türlerinden ayıran unsurlar nelerdir? Etik liderliğin ne gibi bireysel ve örgütsel sonuçları vardır? Bu sorulara yanıt bulmak amacıyla öncelikle etik liderlik konusundaki yazın taramasına yer verilecek, ardından etik liderliğin örgüt açısından sunduğu olumlu sonuçlar tartışılacaktır. Bu araştırma ile etik konusundaki yazına katkı sağlanmış ve gelecekte bu konuda yapılacak çalışmalara öneriler sunulmuştur. 


\section{Etik Liderlik Nedir?}

Örgütsel açıdan etik davranış en sık olarak liderlik ve kültür çerçevesinde incelenmiştir (Mihelič vd., 2010). Brown vd. (2005) etik liderliği, "kişisel eylemler ve kişilerarası ilişkiler yoluyla normatif olarak uygun davranışların gösterilmesi ve bu davranışların takipçilere iki yönlü iletişim, güçlendirme ve karar alma yoluyla tanıtılması" şeklinde tanımlamışlardır. Araştırmacılar (örneğin Brown vd., 2005; Mendonca, 2001), etik liderliğin özellikleri arasında dürüstlük, doğruluk, güvenilirlik, adalet, başkalarına sayg1 ve özgecilik gibi unsurların bulunduğunu belirtmişlerdir. Etik liderler, yaşamlarında etik kurallara uygun hareket eden, adil ve ahlaki olarak uygun karar vericiler olarak nitelendirilmişlerdir (Brown ve Treviño, 2006).

Dion (2009) etik liderliğin yapısı hakkında literatürde mevcut temel karışıklıkları incelemiş ve bunları üç grupta toplamıştır. Birincisi, kültürel ve sosyal açıdan değerlendirildiğinde etnosentrik karışıklıktır. İkincisi, lider tarafından benimsenen değerlerin uygulanıp uygulanmamasından kaynaklanan aksiyolojik karışıklıktır. Üçüncüsü ise "etik" olarak liderliğin felsefi temeliyle ilgili felsefi karışıklık şeklinde tanımlanabilir.

Etnosentrik karışıklık, otokratik liderliğin her zaman etik olmadığını ve dönüşümcü liderliğin ise en etik liderlik tarzı olduğunu savunur. Oysa otokratik liderliğin kesin suretle etik olmadığı sonucu teorik ve ampirik olarak iddia edilemez. Din, kültür gibi faktörler dikkate alındığında otokratik liderlik bazı ülkelerde yaşayanların beklentilerini karşılayabilir. Örneğin birçok Asya ülkesinde değerli olan liderlik stillerine bakıldığında, otokratik liderliğin toplumsal beklentileri karşılayan bir yönetim türü olduğu görülmektedir (Dion, 2009). Blunt ve Jones'un (1997) batı liderlik teorilerini Doğu Asya ve Afrika ülkeleri üzerinde inceledikleri çalışmaları sonucunda, Batıya dayalı kavramların Afrika ve Doğu Asya'da yaygın olarak uygulanamayacağını belirtmişlerdir. Bunun ana nedenleri, otorite, grup sadakati ve kişiler arası uyum ile ilgili değerlerdeki önemli farklılıklar ile ilgilidir.

Öte yandan bazı yazarlar liderliğin ahlaki yönünün temelde dönüşümcü ve karizmatik liderlik ile bir bütün olarak ele almaktadır (Brown vd., 2005). Toor ve Ofori (2009), etik liderliğin dönüşümcü liderliğin tüm 
bileşenleri ile anlamlı ve pozitif olarak ilişkili olduğunu ortaya koymuştur. Bununla birlikte, bazı yazarlar dönüşümcü ve karizmatik liderlerin de etik dışı davranışlar sergileyebileceğini belirtmektedir. Örneğin, Howell ve Avolio (1992), etik ve etik dişı karizmatik liderler olarak kavramı ikiye ayırmıştır.

$\mathrm{Bu}$ noktada etik liderliğin benzer liderlik türlerinden farklarını tartışmak gerekmektedir. Mayer vd. (2009) etik liderliği dönüşümcü liderlik, otantik liderlik gibi kavramın ilişkili olduğu liderlik türlerinden ayıran özellikleri şu şekilde özetlemiştir: Dönüşümcü liderlik gibi liderlik türlerinde etik odaklılık liderliğin yalnızca bir boyutu temsil etmektedir. Buna karşın etik liderliğin tek bir odağı vardır, o da liderin etik yönüdür. Ayrıca etik liderlik özellikle sosyal öğrenme teorisinden yararlanmaktadır. Bu kurama göre, bireyler çalışma ortamında rol modellerin davranışlarını taklit etmeye çalışacak ve modelleme yoluyla öğrenecektir (Bandura, 1986). Bu rol modelleri, çalışma grubundaki lider ve diğer çalışanları içerir. Etik liderlik çerçevesinde sosyal öğrenme kuramı, liderin etik davranışlarının takipçilerinin davranışlarını etik ve olumlu bir yönde etkilediğini vurgulamaktadır. Mayer vd.'nin (2009) yaptıkları araştırma, çalışan davranışlarının hem liderlerinin davranışlarını taklit ettiği bir modelleme sürecinden hem de liderlerin çalışan davranışlarını ödüllendirme ve cezalandırma yetkisi bulunması nedeniyle etkilendiğini ortaya koymuştur. $\mathrm{Bu}$ araştırma bulguları, sosyal öğrenme teorisi öngörülerini desteklemektedir. Ayrıca bu çalışmalara dayanarak, liderlerin etik davranışları ile çalışan davranışlarını olumlu yönde etkileyerek, örgütlerde etik kültürünün oluşması için önemli bir faktör olduklarını söyleyebiliriz.

Bir diğer etik liderlik ile ilgili yanılgı aksiyolojik karışıklıktır. Genellikle ahlaki değerlere sahip liderliğin tanım gereği etik olduğuna inanılır ancak sadece değerlere değil, aynı zamanda bunların örgütsel yaşamda uygulanıp uygulanılmadığına bakılması gereklidir (Dion, 2009). Burada en önemli zorluk, tüm örgütler için ortak etik liderlikle ilgili değerleri belirlemektir çünkü bu değerler, toplumsal kültürlere bağlı olarak da büyük ölçüde değişebilir. Bu doğrultuda Resick, Hanges, Dickson ve Mitchelson (2006) etik liderlik uygulamaların inceledikleri 59 ülkeyi kapsayan kültürlerarası bir çalışma yürütmüşlerdir. Yazarlar yaptıkları yazın taraması sonucunda etik liderliği karakterize eden altı temel özellik belirlemişler- 
dir. Bunlar: karakter ve doğruluk, etik farkındalık, topluluk / insan odaklılık, motive edicilik, teşvik edicilik ve güçlendiricilik ve etik hesap verebilirliği yönetme şeklinde sıralanabilir. Bunlar arasından 4 boyut (karakter / doğruluk, fedakârlık, motive edicilik ve teşvik edicilik) etik liderliğin etkinliği için daha öne çıkmaktadır. Bununla birlikte, her boyutun onaylanmasının kültüre göre önemli ölçüde değiştiği görülmüştür.

Sonuç olarak, etik liderliğin inşası, çeşitli süreçleri birbirine bağlayan bir sistemdir ve bu nedenle, önemli olan bu liderliği teorik olarak etik k1lan şeyin ne olduğunu bilmek değil, etik kuralların liderlik uygulamalarına nasıl somut bir şekilde yerleştirildiğini bilmektir (Dion, 2009).

\section{Etik Liderlik ve İlişkili Olduğu Bazı Kavramlar}

\section{Etik Liderlik ve İş Tatmini İlişkisi}

Artan sayıda araştırma, örgütsel liderliğin çok çeşitli çalışan sonuçları ile bağlantılı olduğunu göstermektedir (Kelloway ve Barling, 2010). Etik liderlik davranışlarının yazında sıkça ilişkilendirildiği kavramlardan biri çalışanın iş tatminidir. İş tatmini, pek çok olumlu örgütsel sonucu sağladığı için en önemli çalışma tutumlarından biri olarak değerlendirilebilir (Saari ve Judge, 2004).

Locke (1976) iş tatminini, iş veya iş deneyimlerini değerlendirilmesi sonucu algılanan memnuniyet veya olumlu duygusal durum olarak tanımlamıştır. Kavramın etkilerini ise dört grup altında toplamıştır. Bunlar: yaşamdan elde edilen doyuma etki, fiziksel sağlığa etki, psikolojik sağlığa etki ve çalışan verimliliğine etki olarak sıralanabilir. Buna karşıt olarak, iş tatminsizliği de pek çok olumsuz sonuca yol açabilmektedir.

Ruiz-Palomino ve Ruiz-Amaya (2011) liderlerin, kurum kültürü ve iklimi üzerinde önemli bir rol oynamasından dolayı, iş tatmini ve etik liderlik arasında önemli bir ilişki olduğunu belirtmişlerdir. Ruiz-Palomino ve Ruiz-Amaya (2011), yürüttükleri ampirik çalışmalarında etik liderliğin doğrudan pozitif şekilde çalışanın iş tatminini etkilediğini ortaya koymuşlardır. Brown vd. (2005) etik liderliğin çalışan memnuniyetini güçlü bir şekilde etkilediğini göstermiştir. 
Benzer şekilde, Kim ve Brymer (2011) otel yöneticileri üzerinde yaptıkları çalışmada, üst düzey yöneticilerin etik liderlik davranışlarının, astlarının iş tatmini ve duygusal örgütsel bağlılıkları ile olumlu yönde ilişkili olduğu kanıtlamışlardır.

Yukarıdaki bilgiler ışığında aşağıdaki önermede bulunulmuştur:

- Önerme 1: Etik liderlik davranışları çalışan memnuniyetini olumlu yönde etkilemektedir.

\section{Etik Liderlik ve İyi Oluş Arasındaki İlişki.}

İş yerinde çalışanın iyi oluşu ve sağlı̆̆ının geliştirilmesi konuları son zamanlarda yazında büyük önem kazanmıştır. Viot ve Benraiss-Noailles (2018), iyi oluşu bir insanın yaşamını algılama ve değerlendirme biçiminden kaynaklanan pozitif bir psikolojik durum olarak tanımlamaktadır.

Liderin davranışları çalışanların psikolojik ve fiziksel iyi oluşları üzerinde etki edebilmektedir. Bu kapsamda, Kelloway ve Barling (2010) liderlerin altında çalışanların sağlığını etkilediğini öne sürmüştür. Örgütlerdeki liderlik davranışları ile çalışanların psikolojik iyi oluşu arasında bir ilişki olduğunu belirtmişlerdir. Farklı liderlik stillerinin çalışanın iyi oluşu üzerindeki etkileri pek çok araştırma ile de kanıtlanmıştır. Örneğin Robertson ve Barling (2014) literatürü incelemiş ve çalışanların fiziksel ve psikolojik iyi oluşlarının istismarcı, serbest bırakıcı ve dönüşümcü liderlik türleri ile ilişkisini analiz etmişlerdir. Yazarlar bu çalışma ile liderliğin çalışanların refahı üzerindeki önemli etkisini anlamamıza yardımcı olmuşlardir.

Liderlik ve iyi oluş arasındaki ilişkinin analiz edildiği bir başka çalışma McMurray vd. (2010) tarafından kâr amacı gütmeyen bir kuruluşta yürütülmüştür. Yazarlar bu çalışmalarında, dönüşümcü liderliğin örgütsel iklim, psikolojik sermaye, çalışan iyi oluşu ve çalışan bağlılığı arasındaki pozitif ilişkileri kanıtlamışlardır. ,

Bununla birlikte etik liderlik ile çalışanların iyi oluşu arasındaki ilişki çok az sayıda araştırmaya konu olmuştur. Bu konudaki ilk çalışmalardan biri Chughtai vd. (2015) tarafından yapılmıştır. Yazarlar iki değişken arasında olumlu ilişkiyi göstermiş ve lidere güvenin etik liderlik ve çalışanın iyi oluş hali arasında aracılık rolü oynadığını ortaya koymuşlardır. Bu kuramsal çerçeveye dayanarak şu önerme yapılabilir: 
- Önerme 2: Etik liderlik davranışları çalışanın iyi oluş hali üzerinde pozitif ve anlamlı düzeyde etkilidir.

\section{Etik liderlik ve örgütsel adalet ilişkisi}

Etik bir liderin temel davranış karakteristikleri arasında adil olmak vardır. Bu nedenle, etik liderlik bir örgütte adaletin sağlanması ile yakından ilgilidir. Örgütsel adalet, iş yerine yönelik çalışanların adalet algısı şeklinde tanımlanabilir ve yaygın olarak üç boyutta incelenmektedir (Greenberg, 1990). Tarihsel olarak en eski geçmişe sahip olan örgütsel adalet boyutu dağıtım adaletidir. Dağıtım adaleti, çalışanların kazanımlarının ya da ödüllerinin performansa göre adil bir şekilde değerlendirerek dağıtılması konusundaki algılardan oluşmaktadır. Adams'ın $(1963,1965)$ eşitlik teorisi dağıtım adaletinin temelini oluşturmaktadır. Eşitlik teorisinde bir çalışan kendinle eş değer pozisyonda gördügü başka bir çalışanla kendini karşılaştırır ve kazançlarıyla harcadığı performans gibi katkılarının oranının diğer çalışanla eşit olmasını bekler. Bu karşılaştırma sonucuna göre çalışanın örgütsel adalet algısı oluşur.

Bir diğer örgütsel adalet boyutu Thibault ve Walker'ın (1975) geliştirdiği süreç adaletidir. Süreç adaleti, çalışanların örgüt tarafından uygulanan süreçlerin adil olduğuna yönelik algılamalarını ifade etmektedir. Diğer bir deyişle süreç adaleti, dağıtım kararlarının alınma süreçlerinin çalışanlar tarafından adil olarak algılanmasına odaklanmaktadır.

Örgütsel adaletin son boyutu olan etkileşimsel adaleti Greenberg (1990), süreç adaletinin kişilerarası yönü olarak nitelemiştir. Süreç adaletine ilişkin algılamalar karar alıcıların çalışanlara yönelik tavırları ve açıklamalarındaki samimiyet gibi faktörlere de bağlı olarak oluşmaktadır. Bu durum etkileşimsel adalet olarak açıklanabilir. Bu anlamda, etkileşimsel adalet genellikle ilk iki adalet boyutundan sonra ortaya çıkar.

Etkileşimsel adalet kişilerarası adalet ve bilgi adaleti olmak üzere iki boyuttan oluşmaktadır (Bies ve Moag, 1986; Colquitt vd. 2001). Kişilerarası adalet, insanlara nezaket, itibar ve saygınlıkla muamele edilme derecesini yansıtırken, bilgi adaleti, süreçler ve sonuçları hakkında açıklamalara dayanmaktadır (Colquitt vd. 2001). 
Etik liderlerin, dağıtım adaleti ile eşitliği sağlaması, süreç adaleti ile kararları alırken sürece etkilenen tarafları dahil etmesi ve etkileşimsel adaleti kullanarak süreçler hakkında saygı çerçevesinde bilgi vermesi beklenir.

Bu kapsamda pek çok araştırmacı etik liderlik ile örgütsel adalet arasındaki ilişkiyi ele almıştır. Örneğin Brown vd. (2005), etik liderliğin, etkileşimsel adalet, dürüstlük ve ideal etki boyutu ile olumlu yönde ilişkili olduğunu ortaya koymuştur. Ayrıca, etik liderlik, liderdeki duygusal güven ile pozitif, kötü niyetli denetim ile de olumsuz yönde ilişkilidir.

Uğurlu ve Üstüner (2011) öğretmenler üzerinde yaptıkları ampirik çalışmada, etik liderliğin örgütsel adaleti olumlu etkilediğini ve örgütsel adaletin de etik liderlik ve örgütsel bağlılık davranışı arasında kısmı aracı rolünü ortaya koymuşlardır. Başka bir çalışma liderin etik davranışlarının örgütte önce etik iklim ardından da süreç adaleti iklimini yarattığını göstermiştir (Shin vd., 2015). Bu doğrultuda aşağıdaki önerme geliştirilebilir:

- Önerme 3: Liderin etik davranışları çalışanın örgütsel adalet alg1sinı pozitif yönde etkilemektedir.

\section{Etik liderlik ve örgütsel vatandaşlık davranışı ilişkisi}

Etik liderliğin çalışan davranışları üzerindeki etkisini incelerken ele alınması gereken bir diğer kavram örgütsel vatandaşlık davranışıdır. Yazında örgütsel vatandaşlık davranışına ilişkin en yaygın tanım Organ'a (1988, 1990) aittir. Organ'a göre örgütsel vatandaşlık davranışı, biçimsel ödül sisteminde doğrudan, tam olarak bulunmayan ve dikkate alınmayan, fakat bir bütün olarak örgütün işlevlerini verimli bir biçimde yerine getirmesine yardımcı olan, gönüllülüğe dayalı davranışlardır. Organ (1997), örgütsel vatandaşlık davranışını beş boyutta ele almıştır. Bunlar: yardımlaşma, nezaket, vicdanlılık, centilmenlik ve sivil erdem olarak siralanabilir.

Etik liderlik ve örgütsel vatandaşlık ilişkisinin incelendiği çalışmalar genellikle sosyal değişim teorisine dayanmaktadır (Kacmar vd., 2011). Sosyal değişim teorisi (Blau, 1964), sosyal değişimin sorumluluk duyguları içerdiğini ve taraflar birbirlerine yarar sağladığında, geleceğe yönelik olumlu geri dönüş beklentisinin oluştuğunu öne sürmektedir. Bu çerçevede etik liderlik davranışlarının, çalışanların örgütsel vatandaşlık davranışı gösterimi yoluyla yanıt verebileceği borçluluk duygularını ortaya çıkarabileceği öne sürülmektedir (Kacmar vd., 2011). 
Mayer vd. (2009) etik liderlik ve örgütsel vatandaşlık ilişkisini ampirik olarak göstermişlerdir. Benzer şekilde, Avey vd. (2011) de liderin etik davranışlarının çalışanların örgütsel vatandaşlık davranışlarını olumlu etkilediğini ortaya koymuşlardır. Bu bilgilerden yola çıkarak etik liderliğin örgütsel vatandaşlık üzerindeki etkisine dair aşağıdaki önerme ortaya çıkmaktadir.

- Önerme 4: Liderin etik davranışları ile çalışanın örgütsel vatandaşlık davranışları arasında pozitif yönde anlamlı ilişki vardır.

\section{Etik liderlik ve örgütsel bağlılık ilişkisi}

Yazında etik liderliğin en çok ilişkilendirildiği bir diğer kavram örgütsel bağlılıktır. Meyer ve Allen (1991) örgütsel bağlılığın üç boyutu olduğunu belirtmiştir. Duygusal bağlılık çalışanın örgüte hissettiği olumlu hisleri nedeniyle kendi isteği sonucu örgütte kalma davranışı şeklinde tanımlanabilir. Devam bağlılı̆̆ı maliyet kazanç hesabına dayanmaktadır. Çalışanın örgütten ayrılması sonucu katlanacağı maliyetlerin kalması durumundaki kazançlarından daha fazla olması nedeniyle örgütte kalmaya devam etmesini ifade etmektedir. Normatif bağlılık ise çalışanın hissettiği görev ve yükümlülük duygusu ile örgütte kalma davranışını ifade etmektedir.

Etik liderlikle ilgili yapılan çalışmalar daha çok örgütsel bağlılığın duygusal boyutuna yöneliktir. Bu doğrultuda Neubert ve arkadaşları (2009), örgütsel bağlılığın duygusal boyutunun etik liderlikle pozitif şekilde ilişkili olduğunu ortaya koymuştur. Aynı şekilde Ruiz-Palomino ve RuizAmaya (2011) etik liderliğin, çalışanların duygusal bağlılığı ile doğrudan ve olumlu yönde ilişkili olduğunu göstermişlerdir. Demirtaş ve Akdoğan’ın (2015) yaptıkları çalışma, yöneticilerin etik liderlik davranışı sayesinde, çalışanlarının işten ayrılma niyetlerini, etik iklim algılarını ve duygusal bağlılıklarını etkileyebileceğini göstermiştir.

Yapılan çalışmalar göstermektedir ki, liderin etik davranışları çalışanın örgütte kalma isteğini arttırmaktadır. Bu nedenle şu önerme öne sürülmüştür:

- Önerme 5: Liderin etik davranışları ile çalışanın örgütsel bağlılığı arasında pozitif yönde anlamlı ilişki vardır. 
$\mathrm{Bu}$ çalışmaya yön veren teorik ve görgül çalışmaların bulguları ışığında Şekil 1'de kuramsal bir model önerisi sunulmaktadır.

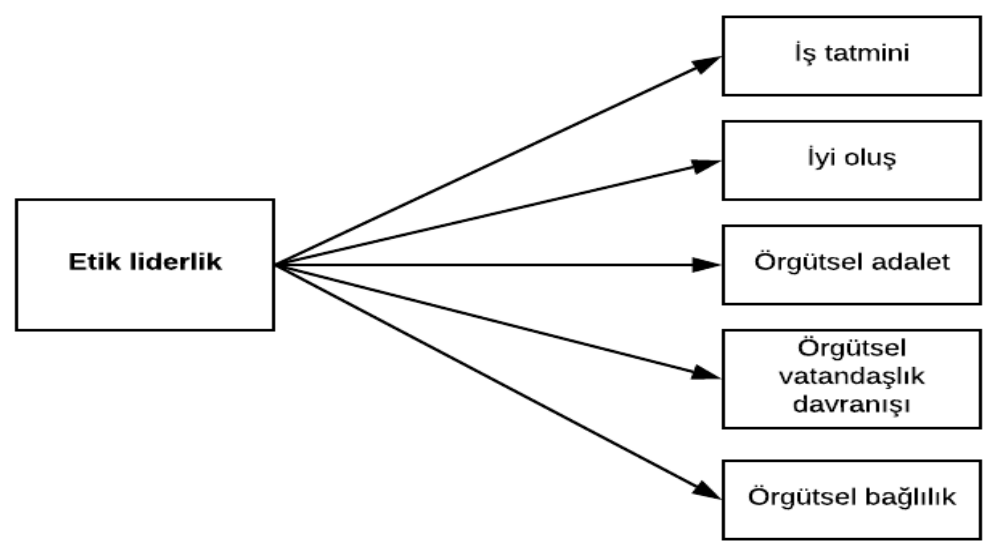

Şekil 1. Etik liderliğin sonuçlarına ilişkin kuramsal model önerisi

Modele göre, liderlerini etik olarak algılayan çalışanların işlerinden memnun olma olasılıkları daha yüksektir. Ayrıca etik liderlik davranışlarının artması çalışanın iyi oluş halini, örgütsel adalet algısını, örgütsel vatandaşlık davranışlarını ve örgüte yönelik bağlılığını doğrudan ve olumlu yönde etkilemektedir. Bu model liderin davranışlarının etik ve adil olarak algılanmasının örgüt açısından önemini de göstermektedir.

\section{Sonuç}

$\mathrm{Bu}$ çalışmada etik liderlik kavramı derinlemesine incelenmiş ve bağlı olduğu değişkenlerle ilişkisi analiz edilmiştir. Çalışmanın literatür taraması sonucunda ortaya koyduğu bulgular, etik liderliğin, liderin ahlaki değerlerinin başkalarını ilgilendiren kararlarda uygulanmasıyla ilgili bir konu olduğunu göstermektedir. Ayrıca etik liderlerin çalışanlarına adil, tarafsız ve dürüst davranması beklenmektedir.

Yazındaki kavram karmaşasını önlemek için etik liderlik ve ilişkili olduğu diğer liderlik türleriyle farkları ortaya konulmuştur. Bu doğrultuda dönüşümcü liderlik gibi olumlu liderlik türleri, etik liderlik davranışla- 
rıyla daha yakından ilgili olmakla beraber, etik odaklılık bu liderlik türlerinin yalnızca bir boyutunu vurgulamaktadır. Etik liderlik ise, liderin çalışanları için etik rol model görevi gördüğü ve etik davranışların önemini çalışanlara uygulayarak gösterdiği bir liderlik şeklidir.

Öte yandan, bazı liderlik türlerini etik liderlikle aynı olarak nitelemek gibi, herhangi bir liderlik türünü etik dışı olarak sınıflandırmak da yanlış olacaktır. Nitekim yazın taraması bulguları, liderlik olgusunun meşruiyetini kültürden aldığını ortaya koymaktadır.

Etik liderlik ile ilgili yapılan araştırmalar kavramın bireysel ve örgütsel sonuçlar üzerinde etkileri olduğunu göstermiştir. Bu doğrultuda çalışmamızda kapsamlı bir model önerisinde bulunulmuştur. Modele göre etik liderliğin örgütler açısından olumlu sonuçlar doğurduğunu söyleyebiliriz. Liderlerin etik davranışları kurumda çalışanların adalet algısını olumlu yönde etkilemektedir. Etik liderlik aynı zamanda çalışanın iyi oluşunun ve örgütsel vatandaşlık davranışının önemli bir belirleyicisidir. Liderin etik davranışları çalışanın iş tatminini arttıran bir unsurdur ve dolayısıyla çalışanın örgüte olan bağlılığını olumlu yönde etkilemektedir. Bu bilgilere dayanarak kurumlara mevcut liderlerini etik davranışlar konusunda eğitmelerini ya da etik liderlik davranışları sergileyen liderler ile çalışmalarını önerebiliriz. Böylelikle rol model olan liderler, çalışanlarını da olumlu yönde davranmaya motive edecek ve kurumlarında etik kültürün oluşmasına katkı sağlayacaklardır.

Etik liderlik konusunda Türkçe yayın azlığı göz önünde bulundurulduğunda bu makale ile önemli bir boşluğun doldurulduğu düşünülmektedir. Öncelikle çalışma konuya ilişkin geniş bir tarama yaparak etik liderlik literatürüne katkı sağlamıştır. Aynı zamanda etik liderliğin yapısının, sonuçlarının ve öneminin anlaşılmasına yardımcı olmuştur. Bununla birlikte çalışmanın bazı kısıtları da bulunmaktadır. Öncelikle bu araştırmada etik liderliğin beş önemli sonucu üstünde durulmuş ve öncülleri ile arac1 etkenler incelenmemiştir. Bundan sonraki çalışmalarda sonuçlar geliştirilip, öncüller de modele katılarak konu daha bütüncül bir yaklaşımla ele alınabilir. Örneğin lidere yönelik güven, kurum itibarı gibi değişkenler modele dahil edilebilir. Öte yandan araştırma modeli kuramsal öneriler üzerine kurulmuştur. Bu bağlamda gelecek araştırmalarda önerilen bağlantılar arasındaki ilişkilerin doğrulanması için araştırma modelinin ampirik olarak test edilmesi yararlı olacaktır. 
EXTENDED ABSTRACT

\title{
The Consequences of Ethical Leadership in Terms of Employees and Organizations: A Conceptual Examination
}

\author{
Belgin Bahar
}

Galatasaray University

Today, due to the ethical scandals, the ethical issue and the ethical leadership concept in businesses have started to gain more importance for enterprises. Leaders should be an essential source of ethical guidance for employees (Brown et al., 2005).

Ethical leadership is a form of leadership about how managers use their power in decisions and actions they take. The power and influence of this form of leadership is based on moral and ethical authority (Akdoğan ve Demirtaş, 2014). Researchers (Brown et al., 2005, Mendonca, 2001) have mentioned that ethical leadership includes attributes such as honesty, integrity, trustworthiness, fairness, respect for others, and alturism.

Many researchers emphasized the importance of the ethical leadership. However, the concept and its characteristics are not fully defined in the literature. In addition, there was some confusion in the literature on the structure of the concept in question.

The aim of this study is to provide a better understanding of the structure of the ethical leadership concept and to analyze its results for the organization and employees. In this contexte, national and international literature was first reviewed and by explaining the concept of ethical leadership the confusions of concept is tried to be resolved. Then, the relations of ethical leadership with other concepts are discussed. Therefore, a theoretical model was proposed to synthesize the results of ethical leadership. 
Brown et al. (2005) define ethical leadership as "the demonstration of normatively appropriate conduct through personal actions and interpersonal relationships, and the promotion of such conduct to followers through two-way communication, reinforcement, and decision-making."

Dion (2009) examined the basic confusion in the literature about the structure of ethical leadership and gathered them into three groups. The first is ethnocentric confusion. Accordingly, it is wrong to argue that autocratic leadership is not always ethical and that transformational leadership is the most ethical leadership style. The types of leadership take their legitimacy from the culture they belong to. Second, it is the axiological confusion about whether the leader applies moral values within the institution. Thirdly, it can be defined as philosophical confusion about the philosophical basis of ethical leadership.

Ethical leadership has several organizational and individual consequences. One of the concepts in which ethical leadership behaviors are frequently associated is employee satisfaction. Ruiz-Palomino and RuizAmaya (2011), in their empirical studies, have demonstrated that ethical leadership directly positively affects the employee's job satisfaction. Brown et al. (2005) showed that ethical leadership has a strong impact on employee satisfaction.

On the other hand, the behavior of the leader can affect the psychological and physical well-being of employees. However, the relationship between ethical leadership and employee well-being has been the subject of very few studies. One of the first studies on this subject is conducted by Chughtai et al. (2015). The authors showed a positive relationship between the two variables and showed that trust in the leader plays an intermediary role between ethical leadership and employee well-being.

Being fair is one of the basic behavioral characteristics of an ethical leader. Therefore, ethical leadership is closely related to the provision of justice in an organization. Many researchers have demonstrated the relationship between ethical leadership and organizational justice.

Another concept that needs to be addressed when examining the impact of ethical leadership on employee behavior is organizational citizenship behavior. Studies investigating the relationship between ethical leadership and organizational citizenship are generally based on social change theory (Kacmar et al., 2011). In this context, it is suggested that ethical 
leadership behaviors can reveal the feelings of indebtedness that employees can respond through the demonstration of organizational citizenship behavior (Kacmar et al., 2011).

Finally, another concept in which ethical leadership is most associated in the litterature is organizational commitment. Studies on ethical leadership are more directed towards the affective dimension of organizational commitment. Studies show that the ethical behavior of the leader increases the employee's desire to stay in the organization.

In the light of the findings of the theoretical and empirical studies leading to this study, a theoretical model is proposed. According to this model, ethical leadership affects employees' job satisfaction, well-being, organizational justice perception, organizational citizenship behavior and organizational commitment directly and positively.

This research reveals the importance of ethical leadership for both the organization and the employees. Based on this study, we can recommand organizations to train their current leaders in ethical behavior or to work with leaders who demonstrate ethical leadership behavior. Thus, the role model leaders will motivate their employees to behave in a positive way and contribute to the formation of an ethical culture in their institutions.

Considering the lack of Turkish literature on ethical leadership, it is thought that an important gap is filled with this article. First, the study contributed to the ethical leadership literature by conducting a broad study on the subject. At the same time, it contributed to understand the structure, results and importance of ethical leadership. However, there are some limitations of the study. First of all, in this research the results of ethical leadership were examined and the antecedents of the concept and intermediary factors were not included. In the following studies, variables such as trust in leader or corporate reputation can be included in the model. In addition, empirical testing of the research model would be useful to verify the relationships between proposed links in future research. 


\section{Kaynakça}

Adams, J. S. (1963). Towards an understanding of inequity. The Journal of Abnormal and Social Psychology, 67(5), 422-436.

Adams, J. S. (1965). Inequity in social Exchange. In Advances in experimental social psychology (Vol. 2) In (pp. 267-299). Academic Press.

Akdoğan, A., ve Demirtaş, Ö. (2014). Etik liderlik davranışlarının etik iklim üzerindeki etkisi: örgütsel politik algılamaların aracı rolü. $A f-$ yon Kocatepe Üniversitesi İktisadi ve İdari Bilimler Fakültesi Dergisi, 16(1), 107-124.

Avey, J. B., Palanski, M. E. and Walumbwa, F. O. (2011). When leadership goes unnoticed: The moderating role of follower self-esteem on the relationship between ethical leadership and follower behavior. Journal of business ethics, 98(4), 573-582.

Bandura, A. and Walters, R. H. (1986). Social learning theory. Englewood Cliffs, NJ: Prentice-hall.

Blau, P. M. (1964). Exchange and power in social life. New York, NY: Wiley.

Blunt, P. and Jones, M. L. (1997). Exploring the limits of Western leadership theory in East Asia and Africa. Personnel Review, 26(1/2), 6-23.

Brown, M. E. and Treviño, L. K. (2006). Ethical leadership: A review and future directions. The leadership quarterly, 17(6), 595-616.

Brown, M. E., Treviño, L. K. and Harrison, D. A. (2005). Ethical leadership: A social learning perspective for construct development and testing. Organizational behavior and human decision processes, 97(2), 117134.

Ciulla, B. J. (2004). Ethics and leadership effectiveness. In J. Antonakis, A. T. Cianciolo and R. J. Sternberg (eds), The nature of leadership, London: Sage 302-327.

Chughtai, A., Byrne, M. and Flood, B. (2015). Linking ethical leadership to employee well-being: The role of trust in supervisor. Journal of Business Ethics, 128(3), 653-663.

Demirtaş, Ö. and Akdoğan, A. (2015). The effect of ethical leadership behavior on ethical climate, turnover intention, and affective commitment. Journal of Business Ethics, 130(1), 59-67. 
Dion, M. (2009). Les confusions entourant le «leadership éthique» dans les organisations. Éthique publique. Revue internationale d'éthique sociétale et gouvernementale, 11(2), 111-128.

Greenberg, J. (1990). Organizational justice: Yesterday, today, tomorrow, Journal of Management, 16, 399-432.

Howell, J. M. and Avolio, B. J. (1992). The ethics of charismatic leadership: submission or liberation?. Academy of Management Perspectives, 6(2), 43-54.

Kacmar, K. M., Bachrach, D. G., Harris, K. J. and Zivnuska, S. (2011). Fostering good citizenship through ethical leadership: Exploring the moderating role of gender and organizational politics. Journal of Applied Psychology, 96(3), 633.

Kelloway, E. K. and Barling, J. (2010). Leadership development as an intervention in occupational health psychology. Work \& Stress, 24, 260-279.

Kim, W. G. and Brymer, R. A. (2011). The effects of ethical leadership on manager job satisfaction, commitment, behavioral outcomes, and firm performance. International Journal of Hospitality Management, 30(4), 1020-1026.

Locke, E. A. (1976). The nature and causes of job satisfaction: in Handbook of industrial and organizational psychology. Chicago: Rand McNally

Mayer, D. M., Kuenzi, M., Greenbaum, R., Bardes, M. and Salvador, R. B. (2009). How low does ethical leadership flow? Test of a trickledown model. Organizational behavior and human decision processes, 108(1), 1-13.

Mayer, D. M., Aquino, K., Greenbaum, R. L. and Kuenzi, M. (2012). Who displays ethical leadership, and why does it matter? An examination of antecedents and consequences of ethical leadership. Academy of Management Journal, 55(1), 151-171.

Mcmurray, A. J., Pirola-Merlo, A., Sarros, J. C. and Islam, M. M. (2010). Leadership, climate, psychological capital, commitment, and wellbeing in a non-profit organization. Leadership \& Organization Development Journal, 31(5), 436-457. 
Mendonca, M. (2001). Preparing for ethical leadership in organizations. Canadian Journal of Administrative Sciences/Revue Canadienne des Sciences de l'Administration, 18(4), 266-276.

Meyer, J. P. and Allen, N. J. (1991). A three-component conceptualization of organizational commitment. Human resource management review, 1(1), 61-89.

Mihelic, K. K., Lipicnik, B., and Tekavcic, M. (2010). Ethical leadership. International Journal of Management ve Information Systems, 14(5), 3141.

Neubert, M. J., Carlson, D. S., Kacmar, K. M., Roberts, J. A. and Chonko, L. B. (2009). The virtuous influence of ethical leadership behavior: Evidence from the field. Journal of Business Ethics, 90(2), 157-170.

Organ, D. W. (1988). Organizational citizenship behavior: The good soldier syndrome. Lexington Books:DC Heath and Com.

Organ, D. W. (1990). The motivational basis of organizational citizenship behavior. Research in organizational behavior, 12(1), 43-72.

Organ, D. W. (1997). Organizational citizenship behavior: It's construct clean-up time. Human performance, 10(2), 85-97.

Resick, C. J., Hanges, P. J., Dickson, M. W. and MITCHELSON, J. K. (2006). A cross-cultural examination of the endorsement of ethical leadership. Journal of Business Ethics, 63(4), 345-359.

Robertson, J. and Barling, J. (2014). Lead well, be well: Leadership behaviors influence employee wellbeing. Wellbeing: A Complete Reference Guide, 1-17.

Ruiz-Palomino, P., Ruiz-Amaya, C. and KNÖRR, H. (2011). Employee organizational citizenship behaviour: The direct and indirect impact of ethical leadership. Canadian Journal of Administrative Sciences/Revue Canadienne des Sciences de l'Administration, 28(3), 244-258.

Saari, L. M. and Judge, T. A. (2004). Employee attitudes and job satisfaction. Human Resource Management: Published in Cooperation with the School of Business Administration, The University of Michigan and in alliance with the Society of Human Resources Management, 43(4), 395-407. 
Shin, Y., Sung, S. Y., Choi, J. N. and Kim, M. S. (2015). Top management ethical leadership and firm performance: Mediating role of ethical and procedural justice climate. Journal of Business Ethics, 129(1), 4357.

Thibault, J. and Walker, L. (1975). Procedural justice: a social psychological analysis. Hillsdale, NJ: Lawrence Elbaum Associates.

Toor, S.-U.-R. and Ofori, G. (2009). Ethical leadership: Examining the relationships with full range leadership model, employee outcomes, and organizational culture. Journal of Business Ethics, 90(4), 533547.

Uğurlu, C. T. ve Üstüner, M. (2011). Öğretmenlerin örgütsel bağlllık düzeylerine yöneticilerinin etik liderlik ve örgütsel adalet davranışlarının etkisi. Hacettepe Üniversitesi Ĕ̆itim Fakültesi Dergisi, 41, 434448.

Viot, C. ve Benrass-Noailles, L. (2018). The Link Between Benevolence and Well-Being in the Context of Human-Resource Marketing. Journal of Business Ethics, March, 1-14.

\section{Kaynakça Bilgisi / Citation Information}

Bahar, B. (2019). Etik liderliğin çalışanlar ve örgütler açısından sonuçları: Kavramsal bir inceleme. OPUS-Uluslararası Toplum AraştırmalartDergisi, 11(18), 2506-2524. DOI: 10.26466/opus.553130 